\title{
PENGARUH KONSENTRASI SURFAKTAN TERHADAP KARAKTERISTIK FISIK NANOEMULSI DAN NANOEMULSI GEL KOENZIM Q10
}

\author{
Silvi Ayu Wulansari*, Ririn Sumiyani, Ni Luh Dewi Aryani \\ Jurusan Farmasi, Fakultas Farmasi, Universitas Surabaya, Indonesia \\ *email: silviayu25@gmail.com
}

Received 18 November 2019

Accepted 31 December 2019

\begin{abstract}
Abstrak
Koenzim Q10 merupakan senyawa yang berfungsi sebagai antioksidan dengan berat molekul yang cukup besar 863,36 g/mol serta memiliki sifat lipofilik. Hal ini yang membuat koenzim Q10 perlu diformulasikan untuk memperbaiki kelarutan bahan dan sistem penghantaran di dalam kulit. Penelitian ini bertujuan untuk mengetahui pengaruh variasi surfaktan (kombinasi PEG-40 HCO dan Span 80) terhadap karakteristik fisik sediaan nanoemulsi dan nanoemulsi gel. Koenzim Q10 diformulasikan menggunakan fase minyak rice bran oil dengan surfaktan kombinasi tersebut. Penelitian ini dibuat dalam 3 formula nanoemulsi yaitu FI, F2, F3 dan 3 formula nanoemulsi gel yaitu F4, F5, F6. Evaluasi karakteristik fisik dilakukan setelah 24 jam setelah sediaan selesai dibuat, pengamatan yang dilakukan meliputi organoleptis (bentuk, warna dan fase yang terbentuk), $\mathrm{pH}$, viskositas, ukuran droplet, zeta potensial dan polidispersity index. Data penelitian diolah secara statistik dengan menggunakan analisis kruskal-Wallis dan uji lanjutan Mann-Whitney. Hasil penelitian menunjukkan bahwa konsentrasi surfaktan berpengaruh terhadap karakteristik fisik (viskositas, ukuran droplet, zeta potensial dan polydispersity index) dengan hasil beda signifikan $(\mathrm{p}<0,05)$ namun konsentrasi surfaktan tidak berpengaruh terhadap $\mathrm{pH}$ dengan hasil tidak beda signifikan $(\mathrm{p}>0,05)$.
\end{abstract}

Kata kunci: Koenzim Q10, Rice bran oil, Surfaktan, Nanoemulsi, Nanoemulsi Gel

\begin{abstract}
Coenzyme Q10 is a compound that functions as an antioxidant with a large molecular weight of $863.36 \mathrm{~g} / \mathrm{mol}$ and has lipophilic properties. This makes coenzyme Q10 need to be formulated to improve the solubility of the material and the delivery system in the skin. This study aims to determine the effect of surfactant variations (a combination of PEG-40 HCO and Span 80) on the physical characteristics of nanoemulsion and nanoemulsion gel preparations. Coenzyme Q10 is formulated using the rice bran oil oil phase with the combination surfactant. This research was made in 3 nanoemulsion formulas FI, F2, F3 and 3 nanoemulsion gel formulas F4, F5, F6. Evaluation of physical characteristics is done after 24 hours after the preparation is complete, observations made include organoleptic (shape, color and phase formed), $\mathrm{pH}$, viscosity, droplet size, zeta potential and polydispersity index. The research data were processed statistically using the Kruskal-Wallis analysis and MannWhitney follow-up tests. The results showed that the surfactant concentration affected physical characteristics (viscosity, droplet size, zeta potential and polydispersity index) with a significantly different result $(\mathrm{p}<0.05)$ but the surfactant concentration did not affect the $\mathrm{pH}$ with the results not significantly different $(\mathrm{p}>0.05)$.
\end{abstract}

Keywords: Coenzyme Q10, Rice bran oil, Surfaktan, Nanoemulsi, Nanoemulsi Gel 


\section{Pendahuluan}

Nanoemulsi merupakan salah satu bagian dari nanoteknologi yang banyak dikembangkan pada nanomedicine dan nanodermatology untuk meningkatan kinerja bahan obat terutama untuk bahan obat yang sukar larut dalam air atau sebalikya (Singh et al., 2016; Setya, et al., 2014).

Koenzim Q10 memiliki beberapa kekurangan untuk diformulasi dalam bentuk sediaan topikal, antara lain kelarutan dalam air yang rendah $(0,193$ $\mu \mathrm{g} / \mathrm{ml})$, berat molekul yang besar $(863,36$ $\mathrm{g} / \mathrm{mol}$ ), dan sifat lipofilisitas yang tinggi $(\log \mathrm{P}>10)$ sehingga membuat Koenzim Q10 tertahan di stratum corneum dan menyebabkan penetrasi dikulit rendah (Lucangioli dan Tripodi, 2012).

Berbagai jenis penelitian tentang sistem penghantaran sebagai pembawa yang efektif dari koenzim Q10 banyak dilakukan yang bertujuan untuk mendapatkan produk dengan bioavailabilitas baik, efektif, dan dapat meningkatkan daya penetrasi ke dalam lapisan kulit (Shoviantari et al., 2017). Sistem penetrasi ke dalam kulit dari sediaan yang buruk dapat berpengaruh terhadap efektivitas bahan obat (Shoviantari et al., 2017).

Berdasarkan penelitian diketahui bahwa salah satu cara untuk meningkatkan penetrasi koenzim Q10 ke dalam kulit melalui pembuatan sediaan melalui sistem penghantaran nanoemulsi, diketahui penetrasi nanoemlusi jauh lebih baik dari sediaan emulsi konvesional (Deapsari et al., 2017). Nanoemulsi memiliki ukuran partikel yang lebih kecil bila dibandingkan emulsi konvesional (Bhatt dan Madhav, 2011).

Secara umum nanoemulsi tersusun dari fase air, fase minyak, kosurfaktan dan surfaktan (Dizaj, 2013). Pemilihan fase minyak sangat mempengaruhi terhadap stabilitas nanoemulsi yang dihasilkan, dimana minyak yang mempunyai rantai pendek sampai sedang lebih stabil bila dibandingkan dengan rantai panjang (Khor et al., 2014). Hal ini dikarenakan minyak yang memiliki rantai pendek sampai sedang lebih mudah dalam proses pemutusan rantai dan menghasilkan sediaan yang lebih jernih bila dibandingkan dengan minyak yang memiliki rantai panjang. Rice bran oil merupakan minyak yang memiliki rantai sedang sehingga memungkinkan menghasilkan sediaan nanoemulsi yang stabil.

Pemilihan bahan seperti minyak dan surfaktan dapat mempengaruhi stabilitas sediaan nanoemulsi (Saifullah. et.,al., 2016). Surfaktan yang biasa digunakan adalah golongan nonionik dikarenakan surfaktan nonionik memiliki sedikit sifat mengiritasi pada penggunaan topical (Kakoty dan Gogoi, 2018). Namun pada beberapa kasus pembuatan nanoemulsi memelukan jumlah surfaktan yang cukup banyak. Jika penggunaan surfaktan dalam jumlah sedikit dapat menyebabkan nanoemulsi tidak stabil. Berdasarkan hal ini, diketahui bahwa penggunaan surfaktan saja tidak cukup untuk menurunkan tegangan permukaan antara fase minyak dan fase air sehingga diperlukan komponen ko-surfaktan untuk membantu menurunkan tegangan permukaan (Sarmah, et.al., 2019) dengan memperbaiki fluiditas antar muka, entropi sistem akan meningkat dan mobilitas ekor hidrokarbon juga akan meningkat sehingga penetrasi minyak kedapam kulit menjadi lebih besar (Kakoty dan Gogoi, 2018).

Pada penelitian sebelumnya yang dilakukan oleh Sukandi (2017) koenzim Q10 diformulasikan dalam bentuk sediaan nanoemulsi dengan fase minyak rice bran oil. Pada hasil uji stabilitas fisik diketahui bahwa formula yang digunakan belum stabil jika dilihat dari parameter uji organoleptis (terjadi perubahan 1 fase menjadi 2 fase) dan $\mathrm{pH}$ sediaan yang bergeser menjadi lebih asam setelah masa simpan selama 30 hari, sehingga dapat disimpulkan bahwa perlu dilakukan 
optimasi surfaktan yang digunakan dalam formula nanoemulsi koenzim Q10 untuk menghasilkan sediaan nanoemulsi dengan sifat karakteristik yang baik (Sukandi, 2017).

Berdasarkan penelitian oleh Sukandi (2017) tersebut, maka penelitian ini bersifat melanjutkan dengan melihat pengaruh variasi komponen surfaktan terhadap karakteristik fisik nanoemulsi. Penelitian ini diharapkan dapat menghasilkan formula nanoemulsi dan nanoemulsi gel koenzim Q10 yang memiliki karakteristik fisik yang baik. Pengamatan karakteristik fisik yang dilakukan meliputi organoleptis (bentuk, warna dan fase yang terbentuk), $\mathrm{pH}$, viskositas, ukuran droplet, zeta potensial dan Polidispersity Index (PI) (Saifullah, et.,al., 2016).

\section{Metode Penelitian}

\section{Pra Formulasi mikroemulsi}

Bahan

Koenzim Q10 (Chemco) Span 80 (Sigma), PEG-40 Hydrogenated castor oil (PEG40- HCO), Etanol 96\% (Merck), Carbomer 940, Trietanolamin (TEA), Aquadem (Universitas Surabaya) Minyak dedak (Rice brand oil), Dapar Phosphate $\mathrm{pH}$ 6,0 $\pm 0,2$ dibuat dari natrium hidroksida dan kalium dihydrogen phosphate (Merck) (Pro Analisis).
Alat

Timbangan analitik (ACIS AD-300i), $\mathrm{pH}$ meter, botol timbang, Gelas ukur (Pyrex), Beaker glass (Pyrex), Hotplate magnetic stirrer (SCILOGEX MS-H280Pro), Kaca arloji, Batang pengaduk, Cawan porselen, Tabung reaksi, Vortex, Pipet tetes, Partikel Size Analizer, viskosimeter Brokfield.

\section{Formulasi \\ Pembuatan Nanoemulsi}

Minyak dedak padi (Rice bran oil) dan Koenzim Q10 dimasukkan kedalam beaker glass diaduk meggunakan magnetic stirrer dengan kecepatan 500 $\mathrm{rpm}$ suhu $50^{\circ} \mathrm{C}$ selama 10 menit, menambahkan Ethanol 96\% sedikit demi sedikit diaduk selama 5 menit. kemudian PEG-40 Hydrogenated castor oil dan Span 80 dimasukkan kedalam beker glas kemudian kecepatan dinaikkan menjadi $700 \mathrm{rpm}$ suhu $50^{\circ} \mathrm{C}$ diaduk selama 10 menit sampai campuran homogen (campuran 1). Memasukkan dapar Phosphate $\mathrm{pH} \quad 6,0 \pm 0,2$ kedalam beaker glass campuran 1 di stirrer dengan keceptan $700 \mathrm{rpm}$ suhu $50^{\circ} \mathrm{C}$ selama 10 menit sampai homogen. Jika campuran telah homogen suhu magnetic stirrer dimatikan, namun tetap diaduk dengan kecepatan 700 rpm selama 10 menit.

Tabel 1. Formula nanoemulsi dan nanoemulsi gel koenzim Q10

\begin{tabular}{llcccccc}
\hline \multirow{2}{*}{ Bahan } & \multirow{2}{*}{ Fungsi } & \multicolumn{4}{c}{ NE } & \multicolumn{4}{c}{ NE Gel } \\
\cline { 2 - 8 } & & F1 & F2 & F3 & F4 & F5 & F6 \\
\hline Q10 & Zat aktif & 0,5 & 0,5 & 0,5 & 0,5 & 0,5 & 0,5 \\
Rice bran oil & Fase Minyak & 4 & 4 & 4 & 4 & 4 & 4 \\
PEG-40 HCO & Surfaktan & 7 & 7 & 6 & 7 & 7 & 6 \\
Span 80 & Surfaktan & 6 & 5 & 6 & 6 & 5 & 6 \\
Ethaol 96\% & kosurfaktan & 3,4 & 3,4 & 3,4 & 3,4 & 3,4 & 3,4 \\
Carbomer 940 & Gelling agent & - & - & - & 1 & 1 & 1 \\
TEA & Alkalizing agent & - & - & - & 1,8 & 1,8 & 1,8 \\
Dapar Phosphate pH 6,0 & Fase air & \multicolumn{4}{c}{ Sampai } & 100 \\
\hline
\end{tabular}

\section{Pembuatan Nanoemulsi Gel}

Minyak dedak padi (Rice bran oil) dan Koenzim Q10 dimasukkan kedalam beaker glass diaduk menggunakan magnetic stirrer dengan kecepatan 500 rpm suhu $50^{\circ} \mathrm{C}$ selama 10 menit, kemudian menambahkan Ethanol 96\% sedikit demi sedikit diaduk selama 5 menit. Kemudian 
PEG-40 Hydrogenated castor oil dan Span 80 dimasukkan kedalam beker glas kemudian kecepatan dinaikkan menjadi $700 \mathrm{rpm}$ suhu $50^{\circ} \mathrm{C}$ diaduk selama 10 menit sampai campuran homogen (campuran 1).

Memasukkan dapar Phosphate $\mathrm{pH}$ 6,0 $\pm 0,2$ kedalam beaker glass yang berbeda kemudian masukkan carbomer 940 kedalam beaker glass yang berisi dapar phosphate aduk menggunakan magnetic stirrer dengan keceptan $1500 \mathrm{rpm}$ suhu $50^{\circ} \mathrm{C}$ selama 10 menit (campuran 2). Mecampurkan TEA kedalam campura 2 diaduk selama 10 menit sampai campuran membentuk massa gel yang homogen (basis gel). Basis gel yang telah terbentuk ditambahkan kedalam campuran 1 kemudian di lanjutkan pengadukan menggunakan ultra turax dengan kecepatan 6000 rpm selama 7 menit.

\section{Evaluasi Karakteristik \\ Organoleptis}

Pengujian dilakukan dengan cara mengamati bentuk, warna, transparasi dan fase yang terbentuk dari sediaan nanoemulsi. Pengamatan ini dilakukan secara visual menggunakan panca indra.

\section{$p H$}

Pengujian $\mathrm{pH}$ dilakukan dengan menggunakan $\mathrm{pH}$ meter Laqua Horiba Scientific yang dikalibrasi terlebih dahulu menggunakan dapar $\mathrm{pH}$ 4,00 dan 7,00 sebelum digunakan untuk mengukur nanoemulsi dan nanoemulsi gel.

\section{Viskositas}

Pengukuran viskositas menggunakan alat viskosimeter Brokfield dengan spindel 64 dengan kecepatan 6 rpm. Sebelum diuji pastikan sampel tersebar secara merata pada permukaan cup serta tidak ada gelembung. Kemudian nyalakan alat beberapa saat sampai pembacaan stabil, catat pembacaan viskositas yang tertera pada display. Nilai viskositas yang diharapkan adalah di bawah 200 cps.

\section{Ukuran Droplet}

Pengujian ukuran droplet dan distribusi ukuran mikroemulsi dilakukan dengan menggunakan alat Partikel Size Analizer. Sampel mikroemulsi $1 \mathrm{ml}$ di encerkan dengan menggunakan $10 \mathrm{ml}$ aqua bidestilata setelah itu di fortex terlebih dahulu sebelum diamati. Data yang diamati adalah diameter droplet rata-rata, polydispersity index (PI) dan zeta potensial.

\section{Analisis Data}

Analisis data yang digunakan untuk mengetahui pengaruh konsentrasi surfaktan terhadap karakteristik fisik nanoemulsi dan nanoemulsi gel adalah analisis kruskal-Wallis dan uji lanjutan Mann-Whitney.

\section{Hasil dan Pembahasan}

Sampel yang digunakan dalam penelitian ini adalah sediaan nanoemulsi yang mengandung bahan aktif koenzim Q10.

Berdasarkan data dalam Tabel 1, diketahui bahwa pada pengujian $\mathrm{pH}$ sediaan nanoemulsi koenzim Q10 yaitu F1 sampai F3 dapat diketahui bahwa variasi konsentrasi surfaktan tidak banyak mempengaruhi $\mathrm{pH}$ sediaan. Namun pada saat formulasi sediaan nanoemulsi gel koenzim Q10 tidak hanya ada penambahan Carbomer 940 manum juga ditambhkan TEA dalam formula hal ini dikarenakan jika tidak ada penambahan TEA pada formula, $\mathrm{pH}$ sediaan dari F4 sampai F6 cenderung asam yaitu 4-5 (tidak sesuai dengan spesifkasi sediaan) (Gambar 1). Bergesernya $\mathrm{pH}$ ke arah asam yang berarti dapar yang digunakan tidak cukup untuk menyangga $\mathrm{pH}$ sediaan agar tetap pada $\mathrm{pH}$ $6,0 \pm 0,2$. Walaupun hasil $\mathrm{pH}$ sediaan bervariatif namun semua formula masih dikatakan memenuhi spesifikasi yang dikehendaki yaitu $\mathrm{pH} \quad 6,0 \pm 0,2$.

Rentang nilai $\mathrm{pH}$ sediaan topikal disesuaikan dengan $\mathrm{pH}$ stabilitas bahan aktif dan nilai $\mathrm{pH}$ kulit (4,5-6,5) (Tranggono dan latifah, 2007). Sediaan 
topikal yang memiliki $\mathrm{pH}$ terlalu asam dapat menyebabkan iritasi pada kulit dan jika terlalu basa basa menyebabkan kulit menjadi bersisik (Yani, 2016).

Tabel 2. Hasil uji karakteristik fisik nanoemulsi dan nanoemulsi gel Q10

\begin{tabular}{lcccccc}
\hline Bahan & F1 & F2 & F3 & F4 & F5 & F6 \\
\hline & $\begin{array}{c}\text { Cairan } \\
\text { kuning } \\
\text { pucat, } \\
\text { jernih, }\end{array}$ & $\begin{array}{c}\text { Cairan } \\
\text { kuning } \\
\text { pucat, } \\
\text { jernih, } \\
1 \text { fase }\end{array}$ & $\begin{array}{c}\text { Cairan } \\
\text { kuning } \\
\text { pucat, } \\
\text { jernih, }\end{array}$ & $\begin{array}{c}\text { Gel } \\
\text { berwarna } \\
\text { kuning, } \\
1 \text { fase }\end{array}$ & $\begin{array}{c}\text { Gel } \\
\text { berwarna } \\
\text { kuning, } \\
1 \text { fase }\end{array}$ & $\begin{array}{c}\text { Gel } \\
\text { berwarna } \\
\text { kuning, } \\
1 \text { fase }\end{array}$ \\
$\begin{array}{l}\text { pH } \\
\text { Viskositas } \\
\text { (cp) }\end{array}$ & 5,94 & 5,95 & 5,95 & 5,99 & 6,00 & 6,06 \\
$\begin{array}{l}\text { Ukuran } \\
\text { Droplet }(\boldsymbol{\mu m})\end{array}$ & 0,9023 & 0,8940 & 0,8800 & 33973 & 31793 & 29453 \\
$\begin{array}{l}\text { Zeta Potensial } \\
\text { (mv) }\end{array}$ & $(-)) 40,23$ & $(-) 25,97$ & $(-) 28,43$ & $(-) 18,20$ & $(-) 25,90$ & $(-) 28,40$ \\
$\begin{array}{l}\text { Polidispersity } \\
\text { Index (PI) }\end{array}$ & 0,0388 & 0,0556 & 0,0565 & 0,4903 & 0,3727 & 0,0191 \\
\hline
\end{tabular}

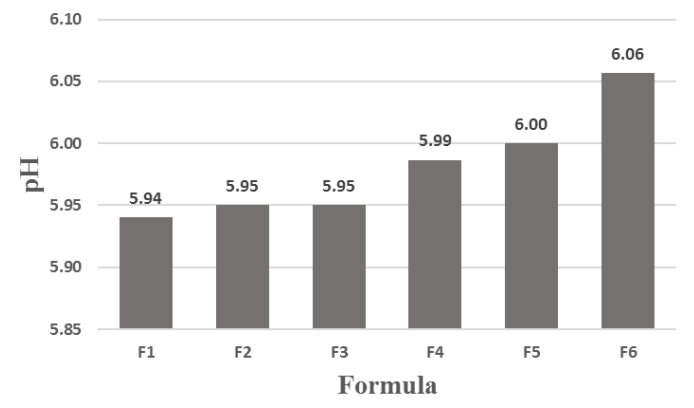

Gambar 1. Pengujian $\mathrm{pH}$ sediaan nanoemulsi dan nanoemulsi gel koenzim Q10

Berdasarkan hasil pengukuran viskositas sediaan nanoemulsi yang hasilnya dapat dilihat pada Gambar 2, diketahui bahwa F1 memiliki total konsentrasi surfaktan yang paling tinggi (13\%), adanya variasi konsentrasi surfaktan berpengaruh terhadap nilai viskositas sediaan nanoemulsi. Hasil pada F2 dan F3 memiliki total konsentrasi surfaktan yang sama yaitu $12 \%$ namun dari data viskositas memiliki nilai yang berbeda disebabkan karena komponen surfaktan yang berbeda pada kedua formula tersebut. Surfaktan pada $F 2$ mengandung jumlah PEG-40-HCO lebih besar dari F3. Diketahui bahwa nilai viskositas dari PEG40-HCO lebih tinggi dari Span 80, hal ini yang mempengaruhi viskositas sediaan menjadi berbeda.

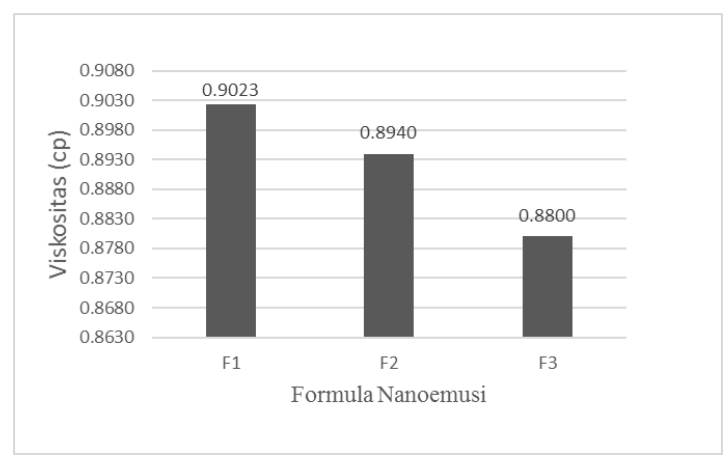

Gambar 2. Pengujian viskositas sediaan nanoemulsi koenzim Q10

Viskositas nanoemulsi gel koenzim Q10 memiliki nilai yang cukup besar, dikarenakan dalam komposisi nanoemulsi gel terdapat carbomer 940 sebagai gelling agent pembentuk masa gel. Dimana konsentrasi carbomer 940 pada F4 - F6 masing-masing sama yaitu $1 \%$, namun nilai viskositas dari ketiga formula memiliki nilai yang berbeda. F4 memiliki nilai viskositas paling tinggi bila dibandingkan dengan F5 dan F6, hal ini serupa dengan yang terjadi pada formula 
nanoemulsi dimana F4 memiliki konsentrasi surfaktan paling tinggi (Gambar 3). Walaupun nilai viskositas antara F4 - F6 berbeda namun nilai viskositas yang diperoleh masih dalam rentang nilai viskositas sediaan gel yang baik ada pada rentang 3.000-50.000 cPs (Pertiwi, 2016).

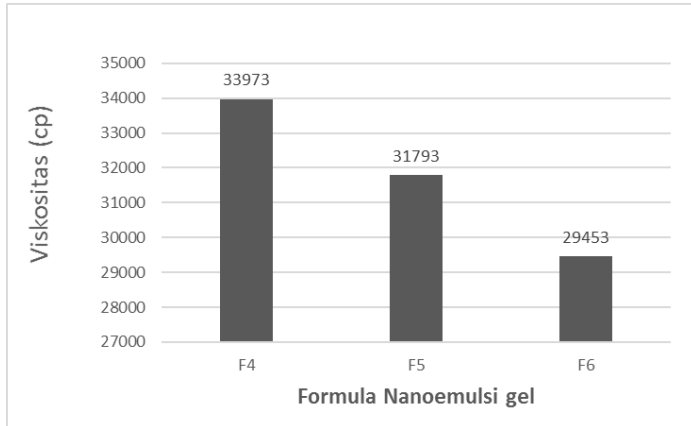

Gambar 3. Pengujian viskositas sediaan nanoemulsi gel koenzim Q10

Penentuan ukuran droplet dan zeta potensial adalah metode yang paling umum digunakan untuk menilai stabilitas dari sediaan nanoemulsi, karena ukuran partikel mengganggu flokulasi dan fenomena koalesensi (Gianeti, et al., 2011). Selain itu ukuran droplet dilakukan untuk mengetahui apakah pemilihan formula dan metode pembuatan sediaan nanoemulsi dan nanoemulsi gel Koenzim Q10 cukup optimal untuk menghasilkan ukuran droplet sesuai spesifikasi yang telah ditentukan yaitu nano partikel dalam rentang nilai 20-200nm (Guan, et al., 2016). Data pengujian ukuran droplet dapat dilihat pada Gambar 4.

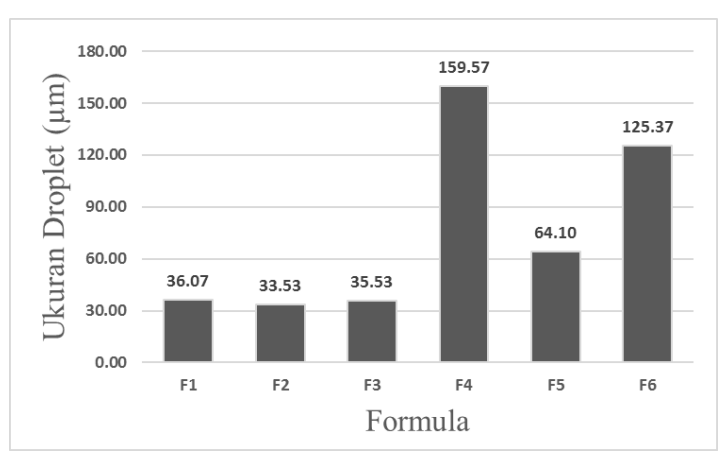

Gambar 4. Pengujian ukuran droplet sediaan nanoemulsi dan nanoemulsi gel koenzim Q10

Pengujian ukuran droplet dapat digunakan sebagai salah satu cara pemilihan surfaktan yang cocok, dimana jika hasil ukuran droplet yang dihasilkan sudah sesuai spesifikasi maka pemilihan surfaktan telah sesuai (Ibrahim, et al., 2015). Hasil evaluasi ukuran droplet pada nanoemulsi F1-F3 memiliki rentang nilai (33,53-36,07) sedangkan untuk nanoemulsi gel F4-F6 memiliki rentang nilai $(64,10-159,57)$ (Gambar 4). Dari hasil diatas dapat diketahui ukuran droplet nanoemulsi dan nanoemlusi gel sesuai spesifikasi nanoemulsi yang memiliki ukuran retang antara 20-200 nm (Guan, et al., 2016).

Nilai zeta potensial jika lebih besar dari | +25 $\mathrm{mV}$ | atau | $-25 \mathrm{mV}$ | menunjukkan stabilitas sistem dari sistem sediaan nanoemulsi, jika nanoemulsi memiliki zeta potensial rendah dan mendekati titik kritis flokulasinya dapat menyebabkan fase yang terbentuk akan mudah mengalami perubahan menjadi 2 fase / pecah (Haidar, et. al., 2017).

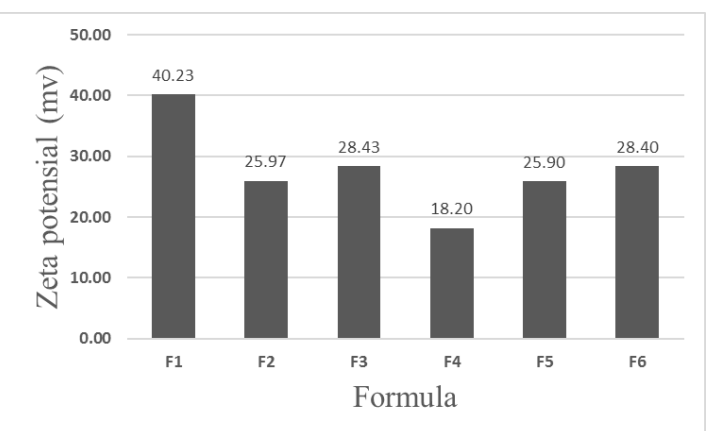

Gambar 5. Pengujian zeta potensial sediaan nanoemulsi dan nanoemulsi gel koenzim Q10

Pada pengujian zeta potensial nilai zeta potensial yang diharapkan berada pada rentang antara $\mid-25 \mathrm{mV}$ | sampai $\mid-30 \mathrm{mV}$ | karena pada rentang nilai tersebut telah cukup untuk menciptakan penghalang energi antar droplet sehingga sediaan nanoemulsi yang terbentuk lebih stabil 
(Shanmugam dan Ashokkumar, 2014).

Berdasarkan Gambar 5, hasil pengujian zeta potensial pada sediaan nanoemulsi F1-F3 memiliki nilai zeta potensial yang sesuai dengan spesifikasi \{lebih besar dari | $-25 \mathrm{mV} \mid\}$, namun pada pengujian sediaan nanoemulsi gel F4-F6 tidak semua formula dapat memenuhi spesifikasi. Semua hasil pengujian zeta potensial menunjukkan angka negatif (-), hal ini mengindikasikan bahwa mayoritas muatan permukaan droplet adalah anionik sehingga mengakibatkan penurunan muatan permukaan droplet menjadi negatif (Chuacharoen et al., 2019).

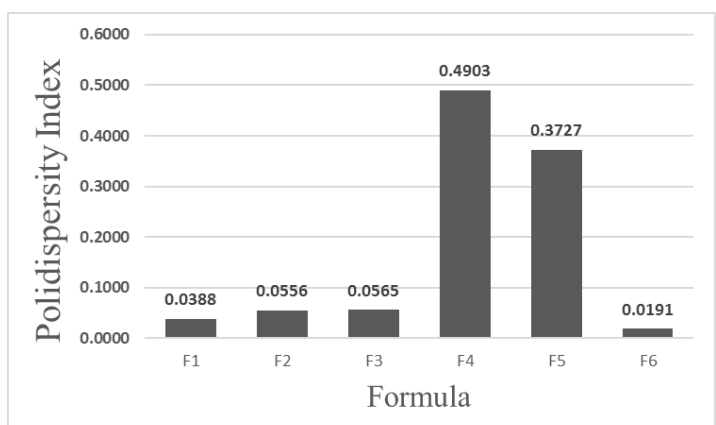

Gambar 6. Pengujian Polidispersity Index (PI) sediaan nanoemulsi dan nanoemulsi gel koenzim Q10

Kriteria sediaan nanoemulsi yang baik adalah sediaan yang terbentuk 1 fase $/$ monodisperse (Saifullah. et.,al., 2016). Hasil pengujian Polidispersity Index (PI) dari keenam formula dapat dilihat pada Gambar 6 diperoleh rentang nilai PI F1-F6 yaitu $(0,0191-0,4903)$. Dimana formula

\section{Daftar Pustaka}

Bhat, P., and Madhav, S., 2011, A detailed review on nanoemulsion drug delivery system, International Journal of Pharmaceutical Sciences and Research, 2(9), 22922298.

Chuacharoen, T., Sehanat P., and Cristina M. S., 2019, Effect of surfactant concentrations on physicochemical properties and functionality of curcumin nanoemulsions under conditions relevant to commercial
F1, F2, F3, F6 memiliki nilai $\mathrm{PI} \leq 0$, 1, hal ini mengindikasikan bahwa sampel merupakan monodisperse / 1 fase. Sedangkan F4 dan F5 memiliki nilai PI $\geq$ 0,1 . Nilai PI yang lebih dekat ke 1 menunjukkan adanya bebagai ukuran droplet dalam sediaan yang mengindikasikan bahwa sampel bukan monodisperse (Tang, et al., 2012).

\section{Kesimpulan}

Beradsarkan hasil penelitian dapat disimpulkan bahwa konsentrasi surfaktan berpengaruh terhadap karakteristik fisik (viskositas, ukuran droplet, zeta potensial dan polydispersity index) dengan hasil beda signifikan $(\mathrm{p}<0,05)$ namun konsentrasi surfaktan tidak berpengaruh terhadap $\mathrm{pH}$ dengan hasil tidak beda signifikan $(p>0,05)$.

\section{Saran}

Penelitian ini perlu dilakukan uji stabilitas secara dipercepat untuk sediaan nanoemulsi dan nanoemulsi gel koenzim Q10 sehingga bisa diketahui stabilitas dari formula.

\section{Ucapan Terima Kasih}

Penulis mengucapkan terimakasih kepada Akademi Farmasi Surabaya selaku institusi dan Fakultas Farmasi Universitas Surabaya yang memfasilitasi dan memberikan banyak dukungan untuk penulis sehingga dapat menyelesaikan penelitian ini.

utilization, Journal Molecules, 24, 2744.

Deapsari, Fani, 2017, Penetration of Ubiquinone (Q10) Nanoemulsion Using Olive Oil Through Rat Skin, International Journal of Pharmaceitical and clinical Research, 9(2), 169-172.

Dizaj, S.M., 2013, Preparation and study of vitamin A palmitate microemulsion drug delivery system and investigation of co- 
surfactant effect. Journal Of Nanostructure in Chemistry, 3, 59.

Gianeti, M.D., Wagemaker, T.A.L., Seixas, V.C., Maia Campos, P.M.B.G., 2011, The use of nanotechnology in cosmetic formulations: The influence of vehicle in the vitamin a skin penetration. Curr, Nanosci., 8, 526-534.

Guan, Y., Wu, J., Zhong, Q., 2016, Eugenol improves physical and chemical stabilities of nanoemulsions loaded with $\beta$ carotene, Food Chem, 194, 787796.

Haidar, I., Harding, I.H., Bowater, I.C., Eldridge, D.S., Charman, W.N., 2017, The role of lecithin degradation on the $\mathrm{pH}$ dependent stability of halofantrine encapsulated fat nano-emulsions, Int. J. Pharm., 528, 524-535.

Kakoty M., Gogoi S.B., 2018, Evaluation of surfactant formulation for EOR in some depleted oil felds of upper Assam. In: Sustainability issues in environmental geotechnics, Springer Nature, Proceedings of the 2nd GeoMEast: international congress and exhibition, 57-75.

Khor, Y.P., Koh, S.P., \& Long, K., et al., 2014, A Comparative Study of the Physicochemical Properties of a Virgin Coconut Oil Emulsion and Commercial Food Supplement Emulsions, Journal Molecules, 19, 9187-9202.

Korkmaz, E., Gokche, E., Ozer, 2013, Developement and Evaluation of Coenzym Q10 Loaded Solid Lipid Nanoparticle Hydrogel for Enhanced Dermal Delivery, Acta Pharm, 63, 517-529.

Lucangioli, S., Tripodi, V, 2012, The Importance Of The Formulation In The Effectiveness Of Coenzyme Q10 Supplementation In Mitochondrial Disease Therapy,
Der Pharmacia Sinica, 3(4), 406407.

Pertiwi, R.D., 2016, Uji Aktivitas Antibakteri Formulasi Gel Untuk Sariawan Dari Ekstrak Daun Saga (Abrus Precatorius Linn.) Terhadap Bakteri Staphylococus Aureus. Jurnal Ilmiah Manuntung: Sains Farmasi dan Kesehatan, 2(2), 239-247.

Saifullah, M., Ahsan, A., Shishir, M.R.I., 2016, Production, stability and application of micro- and nanoemulsion in food production and the food processing industry, In Emulsions; Academic, Press: Cambridge, MA, USA, 405-442.

Sarmah, S., Subrata B.G., Fan X., Annanya A.B., 2019, Characterization and identifcation of the most appropriate nonionic surfactant for enhanced oil recovery. Journal of Petroleum Exploration and Production Technology, 9(34), 383.

Setya, S., Talegaonkar, S., \& Rardan, B., 2014, Nanoemulsion Formulation Methods and Stability, 3(2), 22142228.

Shanmugam, A., Ashokkumar, M., 2014, Ultrasonic preparation of stable flax seed oil emulsions in dairy systems - physicochemical characterization, Food Hydrocoll, 39, 151-162.

Shoviantari, F., Triatiana, E., and Widji, S., 2017, Skin Penetration of Coenzym Q10 in Nanostricture Lipid Carriers Using Olive Oil and Cetyl Palmitate, International Journal of Pharmaceitical and clinical Research, 9(2), 142-145.

Singh, Thakur Gurjeet, and Sharma, Neha, 2016, Chapter 7 Nanobiomaterials in cosmetics: current status and future prospects. Nanobiomaterials in Galenic Formulations and Cosmetics, 
Applications of Nanobiomaterials, 149-174.

Sukandi, C.G., 2017, Karakteristik Fisika$\mathrm{pH}$ dan Stabiltas Nanoemulsi Antiaging. Skripsi. Jurusan Farmasi, Universitas Surabaya.

Tang, S.Y., Manickam, S., Wei, T.K., Nashiru, B., 2012, Formulation development and optimization of a novel Cremophore EL-based nanoemulsion using ultrasound cavitation, Ultrason, Sonochem, 19, 330-345.

Tranggono, R. I., \& Latifah, F., 2007, Buku Pegangan Ilmu Pengetahuan Koasmetik. Jakarta : Gramedia Pustaka Utama.
Yani, T.N., Anwar, E., Saputri, F.C., 2016, Formulasi Emulgel yang Mengandung Ekstrak Daun Binahong (Anredera cordifolia (Ten.) Steenis) dan Uji Aktivitasnya terhadap Propionibacterium acnes secara In Vitro, Jurnal Kefarmasian Indonesia, 6(2): 89-97. 